\begin{tabular}{|c|c|c|}
\hline \multirow{2}{*}{ IDUNAS } & NATURAL \& APPLIED SCIENCES & 2019 \\
& JOURNAL & No. 2 \\
$(1-15)$ \\
\hline
\end{tabular}

\title{
Artificial Photosynthesis with Titania Photocatalysts
}

\author{
Review Article \\ Hüsnü Arda Yurtsever1*iD, Muhsin Çiftçioğlu2 \\ I Adana Alparslan Türkeş Science and Technology University, Department of Materials Engineering, Adana, Turkey \\ 2 Izmir Institute of Technology, Department of Chemical Engineering, İzir, Turkey
}

Author E-mails

husnuarda@gmail.com

Tel: $+903224550000 / 2160$

Fax: +903224550039

*Correspondence to: H.A. Yurtsever, Adana Alparslan Türkeş Science and Technology University,

Department of Materials Engineering, Adana, Turkey

DOI: 10.38061/idunas.658011

Received: December 11, 2019; Accepted: December 31, 2019

\section{Abstract}

Increasing energy demand and global warming due to extensive use of fossil fuels will soon force mankind to use clean and sustainable fuels and artificial photosynthesis is being considered as a promising solution to both problems. Photocatalysis is a light induced process involved in artificial photosynthesis and it will make a great contribution to the solution of environmental problems and generation of renewable energy sources. Titania based photocatalytic materials are one of the widely used materials in artificial photosynthesis research due to their unique chemical and optical properties. Recent research has shown that the activity of titania phases can be improved in the visible light region by several modification techniques. This article aims to present a brief review based on the last 2 decades of global research on the preparation and modification of titania based photocatalysts, their application and importance in artificial photosynthesis and its effect on reducing global warming by the development of a sustainable energy source. This review is mostly based on the $\mathrm{PhD}$ thesis of the corresponding author (Yurtsever, 2015).

Keywords: titania, artificial photosynthesis, global warming, sustainable energy

\section{INTRODUCTION}

Light energy of the sun captured and utilized by plants through photosynthesis processes in which inorganic substances like $\mathrm{CO}_{2}$ and water are consumed for the synthesis of organic compounds necessary for their survival started and sustains the life processes of animals (Collings and Critchley, 2005). The balance in the plant-animal life processes was disturbed by human activities in the last two hundred years. Anthropogenic $\mathrm{CO}_{2}$ emissions increased due to the increasing fossil fuel use since the beginning of industrial revolution and the excess $\mathrm{CO}_{2}$ which cannot be consumed by the plants started to accumulate in the atmosphere. 
In 1824, Jean Baptiste Fourier, a French mathematician, discovered that earth's temperature was rising gradually. This discovery which is about the atmosphere's capturing sunlight escaping and sending it back to the earth, led the basic theory of "Global Warming" arise. This theory was named as the "Greenhouse Effect" since 1990s. Scientific research showed that $\mathrm{CO}_{2}$ emission originating from the fossil fuel usage as the main energy source is the reason for global warming (Collings and Critchley, 2005). Scientists found that earth's global temperature and sea levels raised approximately $0.6{ }_{0} \mathrm{C}$ and $20 \mathrm{~cm}$, respectively, during 20 th century. The average temperature difference reached to $0.6 \mathrm{C}$ by $2000 \mathrm{~s}$. In the year 2100, global $\mathrm{CO}_{2}$ concentration will reach from the present value of 369 ppmv to 650 ppmv unless the fearless fossil fuel consumption was stopped (Houghton, 2004).

Many governments are trying to take precautions by regulations since the discovery and acceptance of global warming. The most important international agreement to fight with the global warming is the "Kyoto Protocol" which was accepted in 1997. According to this protocol, greenhouse gases emissions would have been reduced beginning from 2005 by 125 countries which accepted this protocol (Collings and Critchley, 2005).

\section{ENERGY FROM THE SUN}

Energy from fossil fuels (e.g. oil, coal), nuclear energy and renewable energy (e.g. wind, solar and biomass) are possible choices that can be used to satisfy the energy demand of humanity and sustain life on earth. Geopolitical issues about fossil fuels, capital costs of constructing renewable energy producing facilities directed us to use non-sustainable fossil fuels. More than $80 \%$ of our energy is provided by fossil fuels at present. Our dependence on fossil fuels to create and sustain the well-being and development of society damages the nature irreversibly.

Use of fossil fuels to sustain the energy production until now caused the aforesaid global warming and pollution problem. Increasing energy demand and global warming due to extensive use of fossil fuels will soon force mankind to use clean and sustainable fuels. Solar energy is one of these sustainable energy resources to meet our present and future energy demand. Being limitless and free makes it a promising choice among these renewable resources. The hourly solar energy flux to the earth is more than the energy that we consume in a year. Our energy need can be provided by harvesting $0.02 \%$ of the energy from the sun without using any other energy resources. Solar energy can be converted into electrical energy for the simultaneous production and use or can be converted into heat or chemical energy and stored for the further use (Hammarstrom and Hammes-Schiffer, 2009).

The earth is heated with an energy flux of $1369 \mathrm{~W} / \mathrm{m} 2$ after $30 \%$ of solar energy is absorbed and scattered in the atmosphere. The reason for the loss of energy is the absorption by gases such as water, ozone, $\mathrm{CO}_{2}$ and the scattering by clouds and aerosols in the atmosphere. Light with the wavelengths lower than $300 \mathrm{~nm}$ is absorbed by ozone, nitrogen and oxygen. Absorption in the infrared region is caused by water and $\mathrm{CO}_{2}$. Solar radiation spectrum at the top of the atmosphere and at sea level is given in Figure 1. The solar light with a spectrum between $300 \mathrm{~nm}$ and $2500 \mathrm{~nm}$ reaches to the earth's surface after a portion is absorbed by the atmosphere. Solar radiation consists of three main regions. These are 5\% UV (300-400 $\mathrm{nm}), 40 \%$ visible $(400-800 \mathrm{~nm})$ and $55 \%$ infrared $(800-2500 \mathrm{~nm})$ regions. 


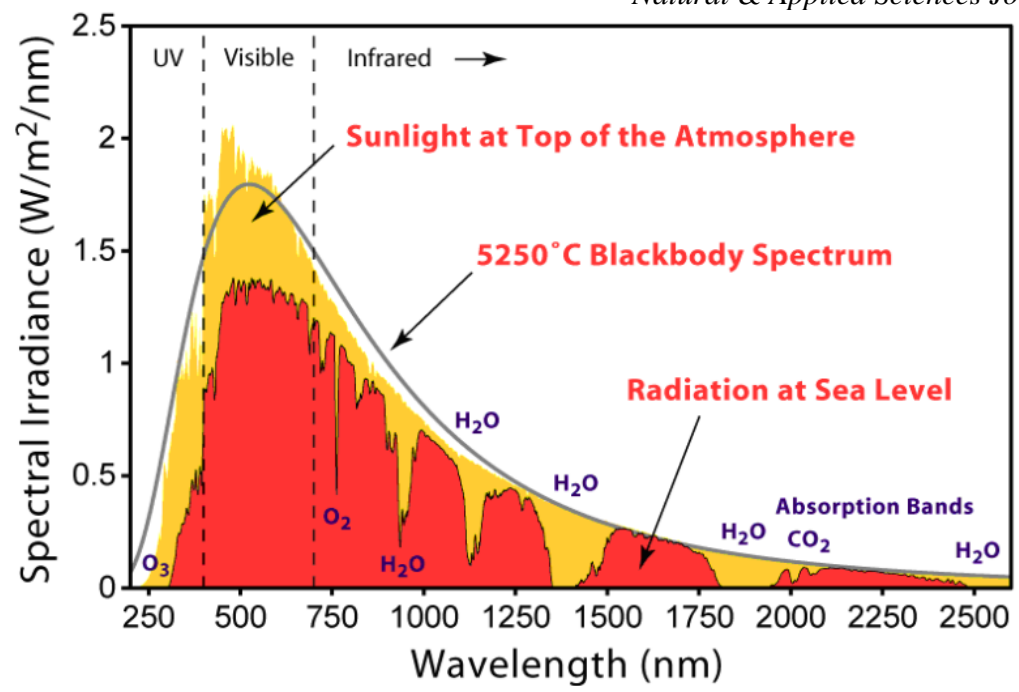

Figure 1. Solar radiation spectrum. (Robert A. Rohde, Global Warming Art project).

\section{UTILIZATION OF SOLAR ENERGY VIA PHOTOCATALYSIS}

Research on the utilization of solar energy to meet the energy demand gained significant interest in the last years. Among the most solar energy utilization techniques, artificial photosynthesis is promising since renewable and sustainable fuels can be generated while global $\mathrm{CO}_{2}$ concentration in the atmosphere is reduced. (Cogdell et al., 2010). The properties of the photocatalyst materials have significant effect on the efficiency of the photocatalytic processes and artificial photosynthesis. These materials should be corrosion resistant (Zhu and Zach, 2009), chemically stable and cheap with high and efficient visible light absorption (Silija et al., 2012).

A photocatalyst is a semiconductor which is mostly an oxide of a metal having a specific band gap energy $\left(E_{g}\right)$ between the conduction and valence band. Semiconductor becomes active when it is exposed to light having photons with energies equal to or higher than the band gap energy of that material (Figure 2). An electron (e-) hops from the conduction band leaving a hole (which can act as a positively charge electron) in the valence band of the semiconductor when the material is excited by photons (Linsebigler et al., 1995).

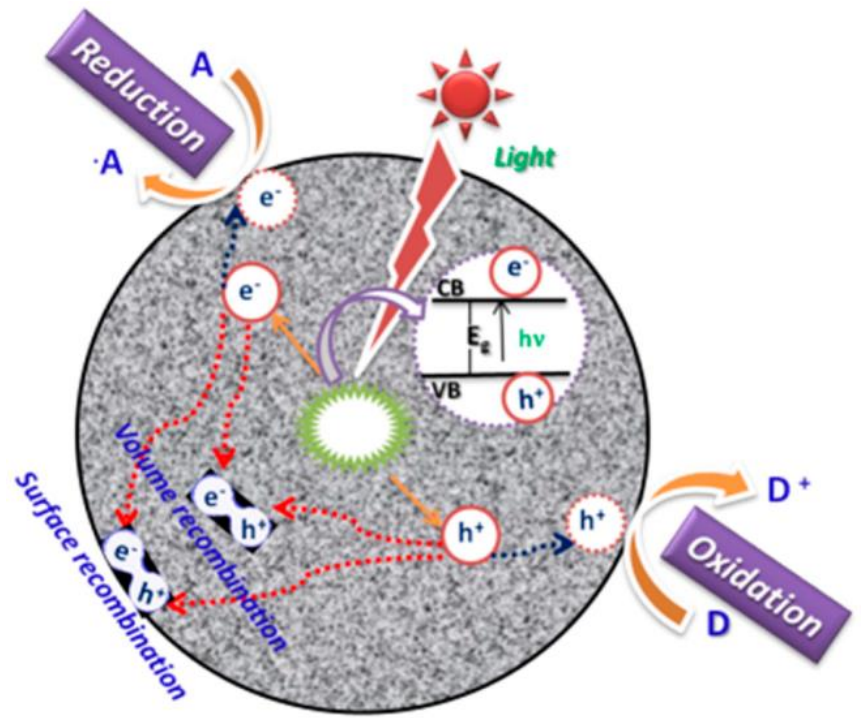

Figure 2. Schematic representation of photocatalysis mechanism (Kumar et al., 2018). 
An ideal photocatalyst should have the following characteristics:

- photoactive,

- biologically and chemically inert,

- photostable (i.e., not prone to photocorrosion),

- inexpensive

- non-toxic.

Photocatalytic processes are started and carried on by the electron-hole pairs $\left(\mathrm{e}_{-}-\mathrm{h}_{+}\right)$which are generated and separated on the surface of the semiconducting material. Excited electrons and holes can react with electron donors/acceptors adsorbed on the surface which triggers oxidation-reduction reactions or recombine/get trapped in surface states becoming useless from the viewpoint of photocatalysis (Zaleska, 2008). Electron-hole pairs generated in the lattice are separated and captured in suitable parts of the nanostructure to avoid recombination on the surface or in the volume. Holes conduct oxidation reactions and electrons conduct reduction reactions (Linsebigler et al., 1995). Electron transfer is more efficient when the reactants are preadsorbed on the surface of the photocatalyst. The probability and the rate of charge transfer process depend strictly on the band edge position of the semiconducting material and the redox potential of the adsorbed species. The bottom of conduction band of the semiconductor must be at a more negative potential than $\mathrm{H}_{+} / \mathrm{H}_{2}(0 \mathrm{~V}$ vs. NHE at $\mathrm{pH} 0)$ and the top of the valence band must be at a more positive potential than $\mathrm{H}_{2} \mathrm{O} / \mathrm{O}_{2}(1.23 \mathrm{~V}$ vs. NHE at $\mathrm{pH} 0)$. The minimum electron energy should be $1.23 \mathrm{eV}$ (the corresponding wavelength is around $1000 \mathrm{~nm}$ ) for water splitting reaction to be thermodynamically possible (Zang, 2011). Some examples of photocatalysts and redox potentials of water splitting and oxidation of organics are given in Figure 3.

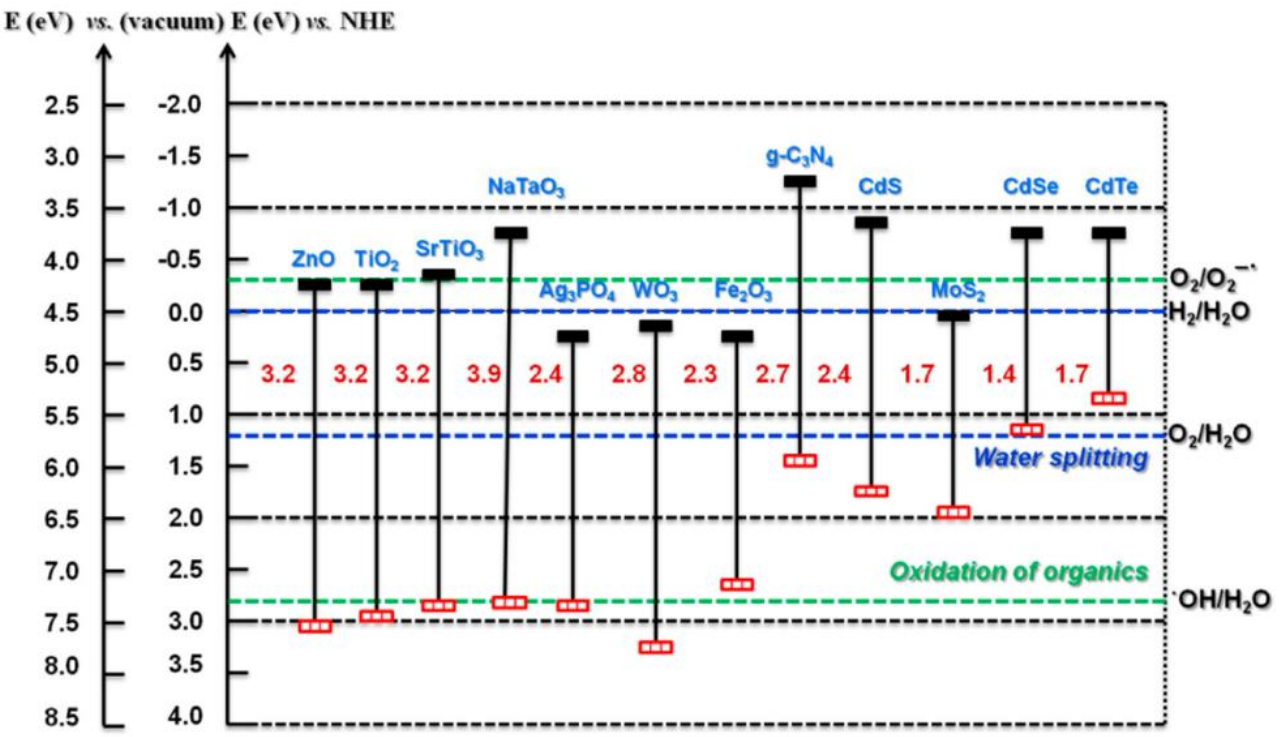

Figure 3. Relationship between band structure of semiconductor and redox potentials of water splitting and oxidation of organics (Kumar et al., 2018).

Nanostructured photocatalytic material preparation techniques were improved and the application area was expanded by the advances in nanotechnology in the last 20 years. Fujishima and Honda conducted the pioneering studies in 1970s to produce renewable energy via artificial photosynthesis and water splitting to produce hydrocarbons and hydrogen (Fusijhima et al., 1972, Inoue et al., 1979). A huge variety of photocatalytic materials to be used in different photocatalytic processes were prepared since Fujishima and Honda. Many oxide, sulfide, nitride based semiconducting materials are used as photocatalysts since they have sufficient band gap energies for photocatalysis. Some examples are $\mathrm{TiO}_{2}, \mathrm{WO}_{3}, \mathrm{SrTiO}_{3} \alpha-\mathrm{Fe}_{2} \mathrm{O}_{3}, \mathrm{ZnO}$, $\mathrm{CuO}, \mathrm{ZnS}, \mathrm{CdS}, \mathrm{CdSe}, \mathrm{GaN}$. The band gap energies of these materials are 3.2, 2.8, 3.2, 3.1, 3.2, 1.2, 3.6, 
2.4, 1.7, $3.4 \mathrm{eV}$, respectively (Hoffman et al., 1995). The boundary of UV and visible light regions is around $3.1 \mathrm{eV}$ photon energy which corresponds to the energy of a light with $400 \mathrm{~nm}$ wavelength. $\mathrm{TiO}_{2}$ is the most extensively used photocatalyst due its favorable properties such as biological and chemical inertness, thermal stability, photo/chemical corrosion stability and being cheap. The main applications of $\mathrm{TiO}_{2} \mathrm{based}$ phocatalysts are: photovoltaics, photoinduced superhydrophilicity and in photocatalysis, organic synthesis, degradation of pollutants, nitrogen fixation and artificial photosynthesis including hydrogen production and $\mathrm{CO}_{2}$ reduction. The diverse applications of $\mathrm{TiO}_{2}$ make it a favorable and preferred material in the photocatalysis area.

\section{NATURAL AND ARTIFICIAL PHOTOSYNTHESIS}

In natural photosynthesis plants and cyanobacteria (which are photoautotrophic) synthesize their own building block materials from inorganic compounds such as $\mathrm{CO}_{2}$, nitrates, sulfates with the help of sunlight energy. Photon energy splits water into oxygen and hydrogen which is then bounded to NADPH (Nicotinamide adenine dinucleotide phosphate). This process, which is called as Light Reactions, is conducted at photosynthesis reaction centers embedded in cell wall and includes the electron transfer related to ATP (Adenozine triphosphate) synthesis. In Dark Reactions, NADPH, ATP and $\mathrm{CO}_{2}$ is consumed in Calvin Cycle (Figure 4) to produce carbohydrates (Gan et al., 2019).

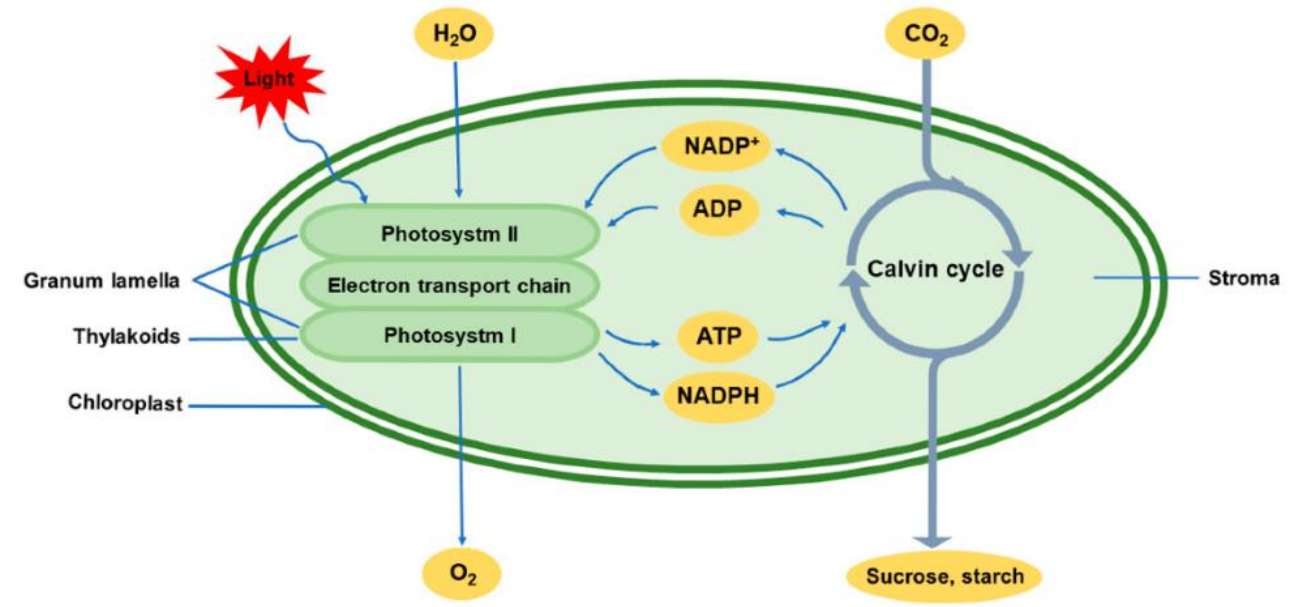

Figure 4. Photosynthesis under normal conditions (Gan et al., 2019).

Biomass, oxygen and also fossil fuels are the products of photosynthesis organized by plants and cyanobacteria. The life on earth is tied to photosynthesis and is a cycle of $\mathrm{CO}_{2}$. Animals are heterotrophic and need carbohydrates/other organics to survive. They provide the energy for their own life processes by using biomass which is produced by plants. $\mathrm{CO}_{2}$ is produced when oxygen is consumed. In brief, sunlight captured and utilized by plants is the source of life and related processes on earth.

Solar energy can be utilized by many different ways. Solar cells can transform solar energy into electricity, solar ponds can store the energy from the sun as heat energy and solar energy can be used to generate steam for turbines or transformed into chemical energy via photocatalysis (Hammarstrom and Hammes-Schiffer, 2009). Each method has its own advantages and disadvantages. Artificial photosynthesis is the mimicking of natural photosynthesis and is one of the common photocatalytic processes which convert $\mathrm{CO}_{2}$ and water into useful chemicals such as methanol, methane, carbon monoxide, other hydrocarbons and hydrogen which can be stored and used as energy source.

$\mathrm{CO}_{2}$ is a linear molecule $(\mathrm{O}=\mathrm{C}=\mathrm{O})$ without a dipole moment and is one of the most stable compounds (but not inert) which is mostly produced by oxidation/combustion reactions. $\mathrm{CO}_{2}$ needs high energy reducing molecules to be converted into hydrocarbons. The Gibbs free energy change of a reaction should be negative in order to be thermodynamically favorable. Most reactions given in Table 1 have positive 
Gibbs free energy changes and reaction of $\mathrm{CO}_{2}$ with $\mathrm{H}_{2} \mathrm{O}$ seems thermodynamically unfavorable. High energy input is needed to convert $\mathrm{CO}_{2}$ into hydrocarbons. Therefore, high temperatures and pressures are needed to activate $\mathrm{CO}_{2}$. In photocatalysis, $\mathrm{CO}_{2}$ can be activated by electrons and react with holes at room temperature and atmospheric pressure by the energy input from the sunlight. Reducing molecules such as $\mathrm{H}_{2}, \mathrm{H}_{2} \mathrm{O}$ or $\mathrm{CH}_{4}$ are needed for this purpose among which $\mathrm{H}_{2}$ seems to be more attractive since the Gibbs free energy changes of the reactions involving $\mathrm{H}_{2}$ are low or negative. However, it is meaningless to reduce $\mathrm{CO}_{2}$ with $\mathrm{H}_{2}$ which has more chemical potential and the system loses its chemical potential by consuming $\mathrm{H}_{2}$. If $\mathrm{H}_{2}$ is produced by water splitting without synthetic energy input e.g. solar energy, not the energy from burning fossil fuels, the process would be feasible.

Table 1. Change of Gibbs free energy at $298 \mathrm{~K}$ for reactions related to the photocatalytic reduction of $\mathrm{CO}_{2}$ to various renewable fuels (Zang, 2011).

\begin{tabular}{|c|c|c|c|}
\hline Reductant & Product & Chemical equation & $\Delta \mathrm{G}^{0}(\mathrm{~kJ} / \mathrm{mol})$ \\
\hline \multirow[t]{3}{*}{$\mathrm{H}_{2}$} & $\mathrm{HCOOH}$ & $\mathrm{CO}_{2}+\mathrm{H}_{2} \rightarrow \mathrm{HCOOH}$ & 43 \\
\hline & $\mathrm{CH}_{3} \mathrm{OH}$ & $\mathrm{CO}_{2}+3 \mathrm{H}_{2} \rightarrow \mathrm{CH}_{3} \mathrm{OH}+\mathrm{H}_{2} \mathrm{O}$ & 4 \\
\hline & $\mathrm{CH}_{4}$ & $\mathrm{CO}_{2}+4 \mathrm{H}_{2} \rightarrow \mathrm{CH}_{4}+2 \mathrm{H}_{2} \mathrm{O}$ & -114 \\
\hline \multirow[t]{3}{*}{$\overline{\mathrm{C}} \overline{\mathrm{H}}_{4}$} & $\overline{\mathrm{C}} \overline{\mathrm{H}_{3}} \overline{\mathrm{C}} \overline{\mathrm{O}} \overline{\mathrm{C}} \overline{\mathrm{H}} \overline{3}$ & $\overline{\mathrm{CO}}_{2}+2 \overline{\mathrm{C}} \mathrm{H}_{4} \rightarrow \overline{\mathrm{C}} \mathrm{H}_{3} \overline{\mathrm{COCH}}_{3}+\overline{\mathrm{H}}_{2} \mathrm{O}$ & $\overline{1} 1 \overline{5}$ \\
\hline & $\mathrm{CH}_{3} \mathrm{COOH}$ & $\mathrm{CO}_{2}+\mathrm{CH}_{4} \rightarrow \mathrm{CH}_{3} \mathrm{COOH}$ & 71 \\
\hline & $\mathrm{HCHO}$ & $\mathrm{CO}_{2}+\mathrm{CH}_{4} \rightarrow 2 \mathrm{HCHO}$ & 240 \\
\hline \multirow[t]{6}{*}{$\overline{\mathrm{H}} \overline{\mathrm{O}} \overline{\mathrm{O}}$} & $\overline{\mathrm{HCOOH}}$ & $-\overline{\mathrm{CO}_{2}}+\overline{\mathrm{H}} 2 \mathrm{O} \rightarrow \overline{\mathrm{HCOOH}}+1 / 2 \mathrm{O}_{2}$ & $\overline{272}$ \\
\hline & $\mathrm{HCHO}$ & $\mathrm{CO}_{2}+\mathrm{H}_{2} \mathrm{O} \rightarrow \mathrm{HCHO}+\mathrm{O}_{2}$ & 521 \\
\hline & $\mathrm{CH}_{3} \mathrm{OH}$ & $\mathrm{CO}_{2}+2 \mathrm{H}_{2} \mathrm{O} \rightarrow \mathrm{CH}_{3} \mathrm{OH}+3 / 2 \mathrm{O}_{2}$ & 690 \\
\hline & $\mathrm{CH}_{4}$ & $\mathrm{CO}_{2}+2 \mathrm{H}_{2} \mathrm{O} \rightarrow \mathrm{CH}_{4}+2 \mathrm{O}_{2}$ & 801 \\
\hline & & $\mathrm{H}_{2} \mathrm{O}(\mathrm{g}) \rightarrow \mathrm{H}_{2}+1 / 2 \mathrm{O}_{2}$ & 229 \\
\hline & & $\mathrm{H}_{2} \mathrm{O}(\mathrm{l}) \rightarrow \mathrm{H}_{2}+1 / 2 \mathrm{O}_{2}$ & 237 \\
\hline
\end{tabular}

The reaction of $\mathrm{CO}_{2}$ with $\mathrm{H}_{2}$ can be carried out either in gaseous or liquid phases. The form of $\mathrm{CO}_{2}$ may vary depending on the phase (gas or a dissolved ion in water). Aqueous solutions of $\mathrm{NaOH}$ are used mostly in order to increase $\mathrm{CO}_{2}$ solubility since it is soluble at high $\mathrm{pH} . \mathrm{CO}_{2}$ dissolves in water according to the following equilibrium reactions (Wojtowicz, 2001):

$$
\begin{aligned}
& \mathrm{CO}_{2}(\mathrm{aq})+\mathrm{H}_{2} \mathrm{O} \leftrightarrow \mathrm{H}_{2} \mathrm{CO}_{3} \\
& \mathrm{H}_{2} \mathrm{CO}_{3} \leftrightarrow \mathrm{H}_{+}+\mathrm{HCO}_{3-} \\
& \mathrm{HCO}_{3-} \leftrightarrow \mathrm{H}_{+}+\mathrm{HCO}_{32-}
\end{aligned}
$$

Some selected redox potentials involving $\mathrm{CO}_{2}$ species and hydrocarbons are given in Table 2. Gaseous $\mathrm{CO}_{2}$ or water dissolved $\mathrm{CO}_{2}\left(\mathrm{H}_{2} \mathrm{CO}_{3}\right)$ can be reduced to $\mathrm{CH}_{3} \mathrm{OH}, \mathrm{CH}, \mathrm{HCOOH}$ with anatase $\mathrm{TiO}_{2}$ whose valence and conduction band potentials are 2.7 and $-0.5 \mathrm{~V}$ versus NHE, respectively. It is also seen that the reduction of gaseous $\mathrm{CO}_{2}$ would be easier due to the closeness of the reduction potentials and conduction band potential of anatase $\mathrm{TiO}_{2}$, however the products of photocatalytic $\mathrm{CO}_{2}$ reduction with $\mathrm{TiO}_{2}$ are not restricted to the given ones in Table 2 since the photocatalytic properties of $\mathrm{TiO}_{2}$ can easily be tuned by several modification methods which may shift the band edge positions or change the reaction mechanism. This table is an illustration of the possible products that may be produced with $\mathrm{TiO}_{2}$. There are reports of gaseous $\mathrm{CO}$ and $\mathrm{CH}_{4}$ production when $\mathrm{CO}_{2}$ reduction was carried out in aqueous conditions (Koci et al., 2009 and 2011, Rajalakshmi et al., 2012). 
Table 2. Summary of reduction potentials for half-cell reactions at $\mathrm{pH} 7$ in aqueous solution vs. the normal hydrogen electrode (Tahir and Amin, 2013).

\begin{tabular}{lc}
\hline \multicolumn{1}{c}{ Chemical equations } & Thermodynamic potential, V vs. NHE \\
\hline $\mathrm{CO}_{2}+\mathrm{e}^{-} \rightarrow \mathrm{CO}_{2}^{-}$ & -2.0 \\
$2 \mathrm{H}^{+}+2 \mathrm{e}^{-} \rightarrow \mathrm{H}_{2}$ & -0.41 \\
$\mathrm{CO}_{2}+2 \mathrm{H}^{+}+2 \mathrm{e}^{-} \rightarrow \mathrm{HCOOH}$ & -0.61 \\
$\mathrm{CO}_{2}+6 \mathrm{H}^{+}+6 \mathrm{e}^{-} \rightarrow \mathrm{CH}_{3} \mathrm{OH}+\mathrm{H}_{2} \mathrm{O}$ & -0.38 \\
$\mathrm{CO}_{2}+8 \mathrm{H}^{+}+8 \mathrm{e}^{-} \rightarrow \mathrm{CH}_{4}+\mathrm{H}_{2} \mathrm{O}$ & -0.24 \\
$\mathrm{H}_{2} \mathrm{CO}_{3}+2 \mathrm{H}^{+}+2 \mathrm{e}^{-} \rightarrow \mathrm{HCOOH}+\mathrm{H}_{2} \mathrm{O}$ & -0.166 \\
$\mathrm{H}_{2} \mathrm{CO}_{3}+6 \mathrm{H}^{+}+6 \mathrm{e}^{-} \rightarrow \mathrm{CH}_{3} \mathrm{OH}+2 \mathrm{H}_{2} \mathrm{O}$ & +0.044 \\
$2 \mathrm{CO}_{3}{ }^{2-}+8 \mathrm{H}^{+}+6 \mathrm{e}^{-} \rightarrow \mathrm{CH}_{3} \mathrm{OH}+2 \mathrm{H}_{2} \mathrm{O}$ & +0.209 \\
\hline
\end{tabular}

The mechanism of photocatalytic reduction of $\mathrm{CO}_{2}$ consists of water splitting and reduction of $\mathrm{CO}_{2}$ with species formed in water splitting reactions. Structural and electronic properties of semiconducting photocatalysts determine the important steps in photocatalysis such as the absorption of photons, charge separation/migration and surface adsorption/reactions. Captured holes react with water adsorbed on the surface of the semiconducting material to produce $\mathrm{O}_{2}$ and $\mathrm{H}+. \mathrm{H} \cdot$ radicals are formed by the interaction of $\mathrm{H}_{+}$ions with excited electrons. Union of two $\mathrm{H}_{+}$ions forms one $\mathrm{H}_{2}$ molecule. These two steps explain the photocatalytic water splitting mechanism. In the presence of $\mathrm{CO}_{2}$, electrons interact with $\mathrm{CO}_{2}$ molecules to form 'CO-radicals (Koci et al., 2009). Newly formed $\mathrm{H} \cdot$ and $\mathrm{CO}$ - radicals react to form $\mathrm{CO}$. Consecutive reactions transform $\mathrm{CO}$ to $\cdot \mathrm{CH}_{3}$ radicals. Finally, $\mathrm{CH}_{4}$ or $\mathrm{CH}_{3} \mathrm{OH}$ molecules are formed when $\cdot \mathrm{CH}_{3}$ radicals react with $\mathrm{H} \cdot$ or $\mathrm{OH}$ - radicals, respectively. These steps along with water splitting steps explain the photocatalytic reduction mechanism of $\mathrm{CO}_{2}$ into hydrocarbons. The recombination of produced electron hole pairs can cause releasing of heat without chemical work which is not desired in photocatalysis.

\section{ARTIFICIAL PHOTOSYNTHESIS WITH TITANIA PHOTOCATALYSTS}

Intensive research on artificial photosynthesis (hydrogen production via water splitting and hydrocarbon production by the reduction of $\mathrm{CO}_{2}$ ) which may become a key process in the future for sustainable energy needs of humanity and global pollution/warming prevention have been conducted in the last 20 years (Wu et al., 2005, Matejova et al., 2014, Raja et al., 2011, Tan et al., 2012, Uner et al., 2011, Zhang et al., 2009). Fujishima and Honda conducted the pioneering study in 1972 to produce hydrogen on a $\mathrm{TiO}_{2}$ electrode (Fusijhima and Honda, 1972) and Inoue et al. (Fujishima and Honda who are the leading researchers of photocatalysis of $\mathrm{TiO}_{2}$ were the co-workers in this study) reported the first photocatalytic reduction of $\mathrm{CO}_{2}$ in aqueous media via photocatalytic processes by using solar energy in 1979 . They used different photocatalysts such as $\mathrm{TiO}_{2}, \mathrm{WO}_{3}, \mathrm{ZnO}, \mathrm{GaP}, \mathrm{CdS}$ and $\mathrm{SiC}$. The products of the reactions were formic acid, methanol, methane and formaldehyde (Inoue et al., 1979). Since then many studies on photoreduction of $\mathrm{CO}_{2}$ were conducted. Early studies of photocatalytic reduction of $\mathrm{CO}_{2}$ involved the use of $\mathrm{SiC}, \mathrm{GaP}, \mathrm{SrTiO}_{3}, \mathrm{WO}_{3}, \mathrm{BaTiO}_{3}, \mathrm{LiNbO}_{3}, \mathrm{CaFe}_{2} \mathrm{O}_{4}, \mathrm{Cu}_{2} \mathrm{O}_{2} \mathrm{H}_{2} \mathrm{O}, \mathrm{ZnS}, \mathrm{CdS}$ photocatalysts by Inoue et al. (1979), Ogura et al. (1992) and Yoneyama (1997). Intensive research on the photoreduction of $\mathrm{CO}_{2}$ by using $\mathrm{TiO}_{2}$ was conducted after this period due to the recognition of its extraordinary properties.

$\mathrm{TiO}_{2}$ has three stable phases which are anatase, rutile, brookite along with three metastable and five high pressure phases. The lattice structures of anatase, rutile and brookite which are the most frequently used phases, are shown in Figure 5. 


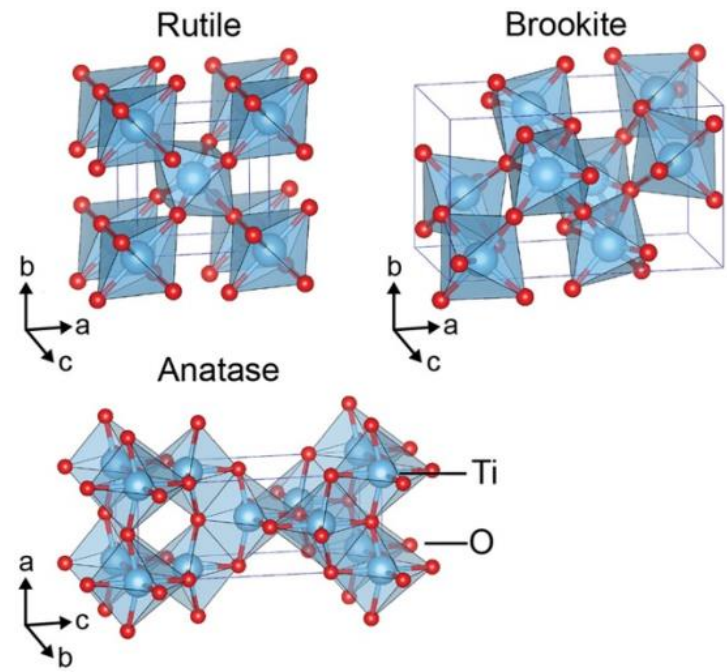

Figure 5. Lattice structures of anatase, rutile and brookite (Haggerty et al., 2017).

$\mathrm{TiO}_{2}$ can be synthesized by various methods for industrial or laboratory uses. Sulfate and chloride methods are widely used for high production rates; however, alkoxide method is widely used in research for lab-scale applications. These methods are based on the chemical source of the desired product, however chemical vapor deposition, precipitation, hydro/solvothermal, sol-gel, emulsion/micro-emulsion, ultrasound/microwave irradiation, spray pyrolysis, electrochemical synthesis are common methods based on different apparatus used and different chemical and physical principles (Anpo and Kamat, 2010). According to the source, Alkoxide Method, according to the principles and apparatus Sol-Gel and Chemical Precipitation Methods along with a brief information about Sulfate and Chloride Method are described below.

\section{Sulfate method}

In sulfate method, titanium oxysulphate $\left(\mathrm{TiOSO}_{4}\right)$ which is formed by dissolving titanium minerals in sulfuric acid is treated with a base to form hydrated $\mathrm{TiO}_{2}$. After heat treatment (calcination) crystalline $\mathrm{TiO}_{2}$ powders are obtained. Hydrated $\mathrm{TiO}_{2}$ synthesized by sulfate method has low photocatalytic activity since it has crystal defects which act as centers for recombination of electron-hole pairs, despite the high surface area. The calcined hydrated $\mathrm{TiO}_{2}$ has also low photocatalytic activity because of the contaminants (sulfate ion or ions from minerals) originating from the method (Gazquez et al., 2014).

\section{Chloride method}

This method is also called as vapor method because titanium minerals are reacted with chlorine gas yielding titanium tetrachloride $\left(\mathrm{TiCl}_{4}\right)$ and oxidized to $\mathrm{TiO}_{2}$ at $700-1000{ }_{\circ} \mathrm{C}$. Crystallization of $\mathrm{TiO}_{2}$ into anatase or rutile also occurs because of the application of high temperatures. Commercially available Degussa P-25 which is commonly used by researchers is synthesized by using this method. Degussa P-25 has $80 \mathrm{wt} . \%$ anatase and $20 \mathrm{wt} . \%$ rutile phases and has a very high photocatalytic activity under UV light illumination (Gazquez et al., 2014).

\section{Alkoxide method (Sol-Gel)}

Metal alkoxides are mostly used precursors for metal oxide synthesis in laboratory scale since the product of sulfate method has contaminations and chlorine method reaction conditions are hard to control. Metal alkoxide can also be produced in highly pure grade which leads to highly pure metal oxide. $\mathrm{TiO}_{2}$ can be synthesized from various titanium alkoxides (e.g. titanium ethoxide, titanium propoxide, titanium butoxide). Titanium alkoxide is hydrolysed to form $\mathrm{TiO}_{2}$ sol/precipitate. $\mathrm{TiO}_{2}$ sol is then gelated to form polymeric $\mathrm{TiO}_{2}$. Proper heat treatment of $\mathrm{TiO}_{2}$ gels leads to highly active $\mathrm{TiO}_{2}$ with high specific surface areas (Kaneko and Okura, 2002). This method is known as the "Sol-gel" method in the literature. Sol-gel 
method has several advantages such as high purity and homogenous product, low temperature synthesis, excellent atomic mixing, precise control of size and surface properties, wide variety of precursors or other chemicals, possibility of different form of products such as films or powders. High amount of solvent usage in this method makes it infeasible for high production rates of $\mathrm{TiO}_{2}$ (Tseng et al., 2010).

\section{Chemical precipitation}

Chemical precipitation is a liquid phase reaction which is used to synthesize insoluble solid particles. Solid particles obtained during precipitation, the precipitate, are formed in the solution due to a reaction or when the solution has been supersaturated by a compound. Titanium precipitates are titanium hydroxide $(\mathrm{Ti}(\mathrm{OH}) 4), \mathrm{TiO}_{2}$ or titanium oxyhydroxide $\left(\mathrm{TiO}(\mathrm{OH})_{3}\right)$. Titanium precursor can be alkoxide based or inorganic (e.g. $\mathrm{TiCl}_{4}$ ). The dissolved precursor solution is mostly precipitated by the use of an alkali solution since $\mathrm{Ti} 4+$ is soluble in acidic conditions. The precipitates can be crystalline or amorphous particles. After a heat treatment, oxide particles can be obtained. Usually an aqueous or alcohol solution of inorganic salt (sulfate, chloride or nitrate) of desired dopant ion is used to modify $\mathrm{TiO}_{2}$ and $\mathrm{Ti}_{4}$ is precipitated with dopant ions in an alkali solution (of $\mathrm{NH}_{4} \mathrm{OH}, \mathrm{NaOH}$ ). Unwanted growth of particles is inevitable during calcination. Thus, direct precipitation from a non-aqueous solution may be carried out in order to obtain ultrafine particles.

The commonly known anatase and rutile phases of titania $\left(\mathrm{TiO}_{2}\right)$ are the most important and widely used materials in environmental related photocatalytic research and applications. The most important disadvantage of these titania phases is their relatively high band gap energies (in the 3.0-3.2 eV range) which results in absorption of sun light in the ultra-violet (UV) range which represents < 5\% of solar radiation spectrum (Nassoko et al., 2012). The reduction and modification of the band gap energies of the titania phases by doping with various elements for more efficient light absorption and the determination of their activities in the photocatalytic degradation of organic molecules and artificial photosynthesis are the main concern of intense research in the last 10-15 years. These dopants comprise heavily nonmetals like C, N, S etc. (Cong et al., 2007, Dong et al., 2011, Park et al., 2006, Rockafellow et al., 2009, Shen et al., 2007, Yang et al., 2010) and transition metals like $\mathrm{Cu}, \mathrm{Ag}, \mathrm{Fe}$, Co etc. (Akpan and Hameed, 2010, Silija et al., 2012, Baiju et al., 2007, Nie et al., 2009). Research conducted in the last 20 years on the effects of titania phase stability and dye decomposition activities have shown that lanthanide incorporation also reduced the band gap energy, widened absorption into the visible light region and increased the photocatalytic activity of $\mathrm{TiO}_{2}$ (Choudhury et al., 2013, Li et al., 2004, Obregon et al., 2013, Ranjit et al., 2001, Xiao et al., 2007).

Band gap engineering for improving the photocatalytic activity of $\mathrm{TiO}_{2}$ can be accomplished by;

- doping $\mathrm{TiO}_{2}$ with various cations/anions (metal or nonmetal) to introduce sub energy levels between the conduction and valence band (Zaleska, 2008),

- combining with low band gap materials; a coupled semiconductor mechanism in which low band gap semiconductor absorbs the photons of visible light and transfers them to the surface of $\mathrm{TiO}_{2}$ (Magesh et al., 2009),

- $\quad$ surface modification (Dugandzic et al., 2012),

- using different synthesis routes to modify the crystallite sizes.

Using different synthesis routes such as chemical vapor deposition, precipitation, hydro/solvothermal, sol-gel, emulsion/micro-emulsion, ultrasound/microwave irradiation, spray pyrolysis, electrochemical synthesis methods, as stated previously, may alter the physicochemical, optical and electronic properties by tuning the surface chemistry, pore structure or crystallinity of $\mathrm{TiO}_{2}$. Phase composition (anatase to rutile weight ratio), crystallite size, band-to-band transitions have significant effect on the band gap energy of semiconductors. Changing the synthesis route may significantly change these properties and thus the band gap energy of $\mathrm{TiO}_{2}$. Combining $\mathrm{TiO}_{2}$ with low band gap materials is also another versatile method to improve the optical properties of $\mathrm{TiO}_{2}$. According to this coupled mechanism, 
a visible light absorbing material can transfer electrons to the conduction band of $\mathrm{TiO}_{2}$ and redox reactions are started by these lower energy charge carriers.

Doping $\mathrm{TiO}_{2}$ with anions/cations is the most preferred one since it is easy to tune the absorption edge by the type or amount of doping ion which leads to the improvement of photocatalytic activity. Interpretations on the contribution of doped ions to the electronic structure of $\mathrm{TiO}_{2}$ can be done considering the valence band of $\mathrm{TiO}_{2}$ is at oxygen $2 \mathrm{p}$ state and conduction band is at titanium $3 \mathrm{~d} \& 4 \mathrm{~s}$ state. Metal doping introduces new energy levels in the band gap of $\mathrm{TiO}_{2}$ which narrows the band gap and improves the light absorption of $\mathrm{TiO}_{2}$. Transition metal doping also enables the trapping of electrons which inhibits the electron-hole recombination and improves oxidation-reduction activity of $\mathrm{TiO}_{2}$. Nonmetal doping improves the light absorption and photocatalytic activity of $\mathrm{TiO}_{2}$ by three mechanisms. First one is the band gap narrowing by hybridization of oxygen $2 p$ with nonmetal $2 p$ by introducing a new valence band closer to the conduction band. Second one is the introduction of isolated impurity levels in which electrons are excited only by visible light. Electrons in the valence band and impurity level are both excited with UV irradiation, however visible light only excites the electrons in the impurity level. Third one is the creation of holes localized in oxygen vacancies forming $\mathrm{O}_{2}$. and $\mathrm{OH}$.. radicals which trigger the oxidation reactions (Zaleska, 2008).

Doping can be achieved by various methods e.g. chemical vapor deposition, ion-assisted sputtering, ion implantation and chemical synthesis methods such as sol-gel and chemical precipitation. Mostly used methods are chemical precipitation and sol-gel which were described previously. Transition metals (such as $\mathrm{V}, \mathrm{Cr}, \mathrm{Fe}, \mathrm{Co}, \mathrm{Ni}, \mathrm{Cu}$ ) and nonmetals $(\mathrm{N}, \mathrm{S}, \mathrm{C}, \mathrm{B}, \mathrm{P}, \mathrm{I}, \mathrm{F})$ doped $\mathrm{TiO}_{2}$ photocatalysts were prepared in various research papers presenting the band gap tuning (Bellardita et al., 2011, Magesh et al., 2009, Zaleska, 2008). An example of UV-Vis Diffuse Reflectance spectrum presenting the band gap tuning and red shift of the absorption edge of $\mathrm{TiO}_{2}$ is given in Figure 6.

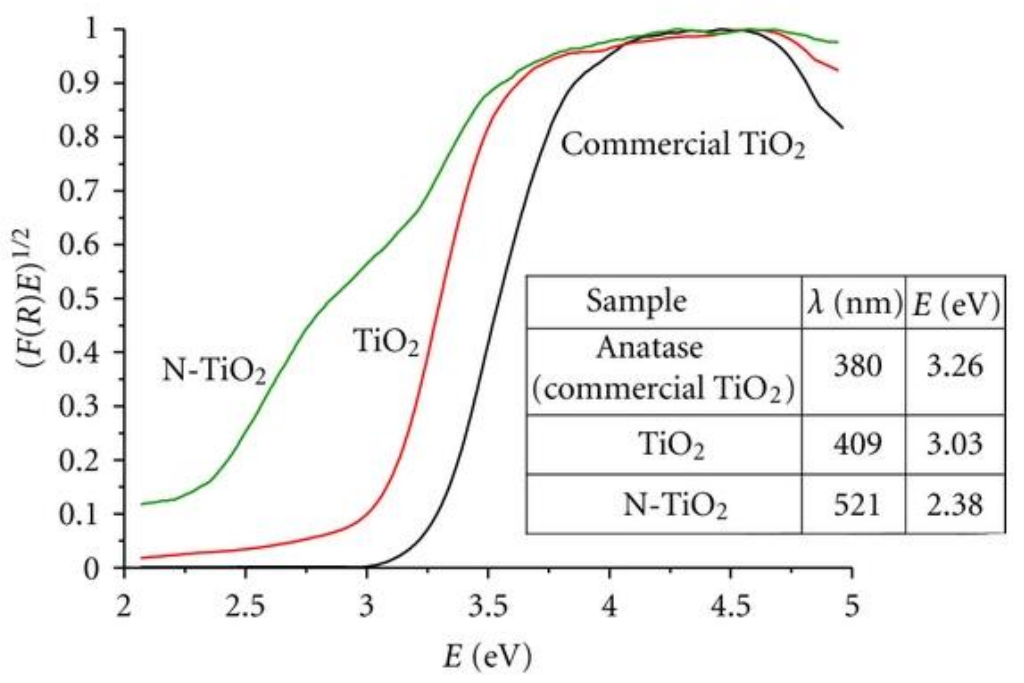

Figure 6. Band gap narrowing of $\mathrm{TiO}_{2}$ by $\mathrm{N}$ doping (Factorovich et al., 2011).

A summary of dopant/composite materials, estimated band gap energies and main products of photocatalytic reduction of $\mathrm{CO}_{2}$ with $\mathrm{TiO}_{2}$ based materials reported in research papers from the last 20 years is given in Table 3. 
Table 3. A brief summary of the last 20 years of photocatalytic reduction of $\mathrm{CO}_{2}$ with $\mathrm{TiO}_{2}$ based materials.

\begin{tabular}{cccc}
\hline $\begin{array}{c}\text { Dopant/ } \\
\text { Composite material }\end{array}$ & $\begin{array}{c}\text { Band gap energy } \\
(\mathbf{e V})\end{array}$ & Main Products & Reference \\
\hline $2.0 \mathrm{wt} \% \mathrm{Cu}$ & $3.0 \mathrm{eV}$ & $\mathrm{MOH}$ & Tseng et al., 2002 \\
$\mathrm{Ru} / \mathrm{SiO}_{2}$ & $3.04 \mathrm{eV}$ & $\mathrm{H}, \mathrm{FA}, \mathrm{FAL}, \mathrm{MN}$ & Sasirekha et al., 2006 \\
$\mathrm{RuBpy}$ & $\mathrm{NA}$ & $\mathrm{MN}$ & Ozcan et al. 2007 \\
$\mathrm{Ag}$ & $2.74 \mathrm{eV}$ & $\mathrm{MN}, \mathrm{MOH}$ & Koci et al. 2010 \\
$\mathrm{N} / \mathrm{nanotube}$ & $3.1 \mathrm{eV}$ & $\mathrm{FA}$ & Zhao et al. 2012 \\
$\mathrm{CeO} 2$ & $2.2 \mathrm{eV}$ & $\mathrm{MN}, \mathrm{CO}$ & Wang et al. 2013 \\
$\mathrm{Pt}$ & $2.06 \mathrm{eV}$ & $\mathrm{MN}$ & Xiong et al. 2015 \\
$\mathrm{Au}-\mathrm{CdS}$ & $2.40 \mathrm{eV}$ & $\mathrm{MN}$ & Wei et al. 2015 \\
$\mathrm{CPO} 27-\mathrm{Mg}$ & $\mathrm{NA}$ & $\mathrm{MN}$ & Wang et al. 2016 \\
$\mathrm{NH} 2-\mathrm{UiO}-66$ & $2.70 \mathrm{eV}$ & $\mathrm{CO}$ & Crake et al. 2017 \\
$\mathrm{CuInS} 2$ & $\mathrm{NA}$ & $\mathrm{MOH}, \mathrm{MN}$ & Xu at al. 2018 \\
$\mathrm{Nd}$ & 1.83 & $\mathrm{CO}$ & Yurtsever et al. 2018 \\
$\mathrm{AuCu}+\mathrm{ZIF}-8$ & $\mathrm{NA}$ & $\mathrm{MN}, \mathrm{CO}$ & Butburee at al. 2019 \\
$\mathrm{C} 3 \mathrm{~N}_{4}$ & 2.34 & $\mathrm{CO}, \mathrm{H}$ & Shi et al. 2019
\end{tabular}

MOH: Methanol, FA: Formic acid, FAL: Formaldehyde, H: Hydrogen, CO: Carbon monoxide, MN: Methane.

\section{CONCLUSION}

Titania photocatalysts used in artificial photosynthesis will contribute to the development of renewable energy resources in the near future by hydrogen production via water splitting and hydrocarbon production via $\mathrm{CO}_{2}$ photoreduction. Research conducted in the last 20 years on titania based materials developed towards photocatalytic water splitting and artificial photosynthesis was briefly reviewed in this paper. The superior properties and chemical stability of titania which was the main reason behind its frequent use in the long past history of artificial photosynthesis will continue to make it a popular and preferred material for use in diverse photocatalytic applications in the near future. This review also shows that titania coupled with recently developed novel materials such as metal organic frameworks and 2D nanosheets may present novel and efficient photocatalysts to be used in artificial photosynthesis.

\section{REFERENCES}

Akpan, U.G., Hameed, B.H. (2010). The advancements in sol-gel method of doped-TiO2 photocatalysts. Applied Catalysis A: General, 375, $1-11$.

Anpo, M., Kamat, P.V., (2010). Environmentally benign photocatalysts applications of titanium oxide-based materials. USA: Springer.

Baiju, K.V., Periyat, P., Wunderlich, W., Krishna Pillai, P., Mukundan, P., Warrier, K.G.K. (2007).
Enhanced photoactivity of neodymium doped mesoporous titania synthesized through aqueous sol-gel method. Journal of Sol-Gel Science and Technology, 43, 283-290.

Bellardita, M., Addamo, M., Di Paola, A., Palmisano, L. (2007). Photocatalytic behaviour of metal-loaded $\mathrm{TiO} 2$ aqueous dispersions and films. Chemical Physics, 339, 94-103.

Butburee, T., Sun, Z., Centeno, A., Xie, F., Zhao, Z., Wu, D. et al. (2019). Improved CO2 
photocatalytic reduction using a novel 3-component heterojunction. Nano Energy, 62, 426-433.

Choudhury, B., Borah, B., Choudhury, A. (2013). $\mathrm{Ce}-\mathrm{Nd}$ codoping effect on the structural and optical properties of $\mathrm{TiO} 2$ nanoparticles. Materials Science and Engineering: B, 178, 239-247.

Cogdell, R.J., Brotosudarmo, T.H.P., Gardiner, A.T., Sanchez, P.M., Cronin, L. (2010). Artificial photosynthesis - solar fuels: current status and future prospects. Biofuels, 1, 861-876.

Collings, A.F., Critchley, C., (2005). Artificial photosynthesis from basic biology to industrial application. Germany: Wiley-VCH.

Cong, Y., Zhang, J., Chen, F., Anpo, M. (2007). Synthesis and characterization of nitrogen-doped TiO2 nanophotocatalyst with high visible light activity. The Journal of Physical Chemistry C, 111, 6976-6982.

Crake, A., Christoforidis, K. C., Kafizas, A., Zafeiratos, S., \& Petit, C. (2017). CO2 capture and photocatalytic reduction using bifunctional TiO2/MOF nanocomposites under UV-vis irradiation. Applied Catalysis B: Environmental, 210, 131-140.

Dong, F., Guo, S., Wang, H., Li, X., Wu, Z. (2011). Enhancement of the visible light photocatalytic activity of c-doped $\mathrm{TiO} 2$ nanomaterials prepared by a green synthetic approach. The Journal of Physical Chemistry C, 115, 13285-13292.

Dugandžić, I.M., Jovanović, D.J., Mančić, L.T., Zheng, N., Ahrenkiel, S.P., Milošević, O.B., Šaponjić, Z.V., Nedeljković, J.M. (2012). Surface modification of submicronic $\mathrm{TiO} 2$ particles prepared by ultrasonic spray pyrolysis for visible light absorption. Journal of Nanoparticle Research. 14, 1-11.

Factorovich M., Guz L., Candal R. (2011). N-TiO2: chemical synthesis and photocatalysis. Advances in Physical Chemistry, 2011, 821204.
Fujishima, A., Honda, K. (1972). Electrochemical photolysis of water at a semiconductor electrode. Nature, 238, 37-38.

Gan, P., Liu, F., Li, R., Wang, S., \& Luo, J. (2019). Chloroplasts-beyond energy capture and carbon fixation: tuning of photosynthesis in response to chilling stress. International Journal of Molecular Sciences, 20(20), 5046.

Gázquez, M.J., Bolívar, J.P., Garcia-Tenorio, R., Vaca, F. (2014). A review of the production cycle of titanium dioxide pigment. Materials Sciences and Applications, 05, 441-458.

Haggerty, J.E.S., Schelhas, L.T., Kitchaev, D.A. (2017). High-fraction brookite films from amorphous precursors. Scientific Reports, 7, 15232.

Hammarstrom, L., Hammes-Schiffer, S. (2009). Artificial photosynthesis and solar fuels. Accounts of Chemical Research, 42, 1859-1860.

Hoffmann, M.R., Martin, S.T., Choi, W., Bahnemann, D.W. (1995). Environmental applications of semiconductor photocatalysis. Chemical Reviews, 95, 69-96.

Houghton, J. (2004). Global warming the complete briefing. USA: Cambridge University Press.

Inoue, T., Fujishima, A., Konishi, S., Honda, K. (1979). Photoelectrocatalytic reduction of carbon dioxide in aqueous suspensions of semiconductor powders. Nature, 277, 637-638.

Kaneko, M., Okura I. (2002). Photocatalysis : science and technology. Kodansha: Springer.

Kočí, K., Obalová, L., Matějová, L., Plachá, D., Lacný, Z., Jirkovský, J., Šolcová, O. (2009). Effect of $\mathrm{TiO} 2$ particle size on the photocatalytic reduction of CO2. Applied Catalysis B: Environmental, 89, 494-502.

Kočí, K., Matějů, K., Obalová, L., Krejčíková, S., Lacný, Z., Plachá, D., Čapek, L., Hospodková, A., Šolcová, O. (2010). Effect of silver doping on the 
$\mathrm{TiO} 2$ for photocatalytic reduction of $\mathrm{CO} 2$. Applied Catalysis B: Environmental, 96, 239-244.

KočÍ, K., ZatloukalovÁ, K., ObalovÁ, L., KrejČÍKovÁ, S., LacnÝ, Z., ČApek, L., HospodkovÁ, A., ŠOlcovÁ, O. (2011). Wavelength effect on photocatalytic reduction of $\mathrm{CO} 2$ by $\mathrm{Ag} / \mathrm{TiO} 2$ catalyst. Chinese Journal of Catalysis, 32, 812-815.

Kumar, S., Karthikeyan, S., Lee, A.F. (2018). gc3n4-based nanomaterials for visible light-driven photocatalysis. Catalysts, 8, 74.

Li, F.B., Li, X.Z., Hou, M.F. (2004). Photocatalytic degradation of 2-mercaptobenzothiazole in aqueous La3+-TiO2 suspension for odor control. Applied Catalysis B: Environmental, 48, 185-194.

Linsebigler, A.L., Lu, G., Yates, J.T. (1995). Photocatalysis on $\mathrm{TiO} 2$ surfaces: principles, mechanisms, and selected Results. Chemical Reviews, 95, 735-758.

Magesh, G., Viswanathan, B., Viswanath, R.P., Varadarajan, T.K. (2009). Photocatalytic behavior of $\mathrm{CeO} 2-\mathrm{TiO} 2$ system for the degradation of methylene blue. Indian Journal of Chemistry, 48A, 480-488.

Matějová, L., Kočí, K., Reli, M., Čapek, L., Hospodková, A., Peikertová, P., Matěj, Z., Obalová, L., Wach, A., Kuśtrowski, P., Kotarba, A. (2014). Preparation, characterization and photocatalytic properties of cerium doped TiO2: On the effect of $\mathrm{Ce}$ loading on the photocatalytic reduction of carbon dioxide. Applied Catalysis B: Environmental, 152-153, 172-183.

Nassoko, D., Li, Y.-F., Li, J.-L., Li, X., Yu, Y. (2012). Neodymium-doped $\mathrm{TiO} 2$ with anatase and brookite two phases: mechanism for photocatalytic activity enhancement under visible light and the role of electron. International Journal of Photoenergy, 2012, 1-10.

Nie, X., Zhuo, S., Maeng, G., Sohlberg, K. (2009). Doping of $\mathrm{TiO} 2$ polymorphs for altered optical and photocatalytic properties. International Journal of Photoenergy, 2009, 1-22.

Obregón, S., Kubacka, A., Fernández-García, M., Colón, G. (2013). High-performance Er3+-TiO2 system: Dual up-conversion and electronic role of the lanthanide. Journal of Catalysis, 299, 298-306.

Ogura, K., Kawano, M., Yano, J., Sakata, Y. (1992). Visible-light-assisted decomposition of $\mathrm{H} 2 \mathrm{O}$ and photomethanation of $\mathrm{CO} 2$ over $\mathrm{CeO} 2-$ $\mathrm{TiO} 2$ catalyst. Journal of Photochemistry and Photobiology A: Chemistry. 66, 91-97.

Ozcan, O., Yukruk, F., Akkaya, E., Uner, D. (2007). Dye sensitized artificial photosynthesis in the gas phase over thin and thick $\mathrm{TiO} 2$ films under UV and visible light irradiation. Applied Catalysis B: Environmental, 71, 291-297.

Park, J.H., Kim, S., Bard, A.J. (2006). Novel carbon-doped $\mathrm{TiO} 2$ nanotube arrays with high aspect ratios for efficient solar water splitting. Nano Letters. 6, 24-28.

Raja, K.S., Smith, Y.R., Kondamudi, N., Manivannan, A., Misra, M., Subramanian, V. (2011). CO2 photoreduction in the liquid phase over pd-supported on $\mathrm{TiO} 2$ nanotube and bismuth titanate photocatalysts. Electrochemical and SolidState Letters, 14, F5-F8.

Rajalakshmi, K., Jeyalakshmi, V., Krishnamurthy, K.R., Viswanathan, B. (2012). Photocatalytic reduction of carbon dioxide by water on titania: role of photophysical and structural properties. Indian Journal of Chemistry. 51A, 411-419.

Ranjit, K.T., Willner, I., Bossmann, S.H., Braun, A.M. (2001). Lanthanide oxide doped titanium dioxide photocatalysts: effective photocatalysts for the enhanced degradation of salicylic acid and tcinnamic acid. Journal of Catalysis. 204, 305-313.

Rohde, Robert A., Solar radiation spectrum, (http://www.globalwarmingart.com/), licence: https://creativecommons.org/licenses/bysa/3.0/deed.en. 
Rockafellow, E.M., Stewart, L.K., Jenks, W.S. (2009). Is sulfur-doped $\mathrm{TiO} 2$ an effective visible light photocatalyst for remediation?. Applied Catalysis B: Environmental. 91, 554-562.

Sasirekha, N., Basha, S., Shanthi, K. (2006). Photocatalytic performance of $\mathrm{Ru}$ doped anatase mounted on silica for reduction of carbon dioxide. Applied Catalysis B: Environmental. 62, 169-180.

Shen, H., Mi, L., Xu, P., Shen, W., Wang, P.-N. (2007). Visible-light photocatalysis of nitrogendoped $\mathrm{TiO} 2$ nanoparticulate films prepared by lowenergy ion implantation. Applied Surface Science. 253, 7024-7028.

Shi, H., Long, S., Hu, S., Hou, J., Ni, W., Song, C. et al. (2019). Interfacial charge transfer in $0 D / 2 D$ defect-rich heterostructures for efficient solardriven $\mathrm{CO} 2$ reduction. Applied Catalysis $B$ : Environmental, 245, 760-769.

Silija, P., Yaakob, Z., Suraja, V., Binitha, N.N., Akmal, Z.S. (2012). An enthusiastic glance in to the visible responsive photocatalysts for energy production and pollutant removal, with special emphasis on titania. International Journal of Photoenergy. 2012, 1-19.

Tahir, M., Amin, N.S. (2013). Recycling of carbon dioxide to renewable fuels by photocatalysis: prospects and challenges. Renewable and Sustainable Energy Reviews. 25, 560-579.

Tan, J.Z.Y., Fernández, Y., Liu, D., Maroto-Valer, M., Bian, J., Zhang, X. (2012). Photoreduction of $\mathrm{CO} 2$ using copper-decorated $\mathrm{TiO} 2$ nanorod films with localized surface plasmon behavior. Chemical Physics Letters. 531, 149-154.

Tseng, I.H., Chang, W.-C., Wu, J.C.S. (2002). Photoreduction of $\mathrm{CO} 2$ using sol-gel derived titania and titania-supported copper catalysts. Applied Catalysis B: Environmental. 37, 37-48.

Tseng, T.K., Lin, Y.S., Chen, Y.J., Chu, H. (2010). A review of photocatalysts prepared by sol-gel method for VOCs removal. International Journal of Molecular Sciences. 11, 2336-2361.
Uner, D., Oymak, M.M., İpek, B. (2011). CO2 utilisation by photocatalytic conversion to methane and methanol. International Journal of Global Warming. 3, 142-162.

Wang, Y., Li, B., Zhang, C., Cui, L., Kang, S., Li, X., Zhou, L. (2013). Ordered mesoporous CeO2TiO2 composites: highly efficient photocatalysts for the reduction of $\mathrm{CO} 2$ with $\mathrm{H} 2 \mathrm{O}$ under simulated solar irradiation. Applied Catalysis B: Environmental. 130-131, 277-284.

Wang, M., Wang, D., \& Li, Z. (2016). Selfassembly of CPO-27-Mg/TiO2 nanocomposite with enhanced performance for photocatalytic $\mathrm{CO} 2$ reduction. Applied Catalysis B: Environmental, 183, 47-52.

Wei, Y., Jiao, J., Zhao, Z., Liu, J., Li, J., Jiang, G. et al. (2015). Fabrication of inverse opal TiO2supported Au@CdS core-shell nanoparticles for efficient photocatalytic CO2 conversion. Applied Catalysis B: Environmental, 179, 422-432.

Wojtowicz, J.A. (2001). The carbonate system in swimming pool water. Journal of the Swimming Pool and Spa Industry. 4, 54-59.

Wu, J.C.S., Lin, H.-M., Lai, C.-L. (2005). Photo reduction of $\mathrm{CO} 2$ to methanol using optical-fiber photoreactor. Applied Catalysis A: General. 296, 194-200.

Xiao, Q., Si, Z., Zhang, J., Xiao, C., Yu, Z., Qiu, G. (2007). Effects of samarium dopant on photocatalytic activity of $\mathrm{TiO} 2$ nanocrystallite for methylene blue degradation. Journal of Materials Science. 42, 9194-9199.

Xiong, Z., Wang, H., Xu, N., Li, H., Fang, B., Zhao, Y. et al. (2015). Photocatalytic reduction of CO2 on $\mathrm{Pt} 2+-\mathrm{Pt} 0 / \mathrm{TiO} 2$ nanoparticles under UV/Vis light irradiation: A combination of $\mathrm{Pt} 2+$ doping and $\mathrm{Pt}$ nanoparticles deposition. International Journal of Hydrogen Energy, 40(32), 10049-10062.

Xu, F., Zhang, J., Zhu, B., Yu, J., \& Xu, J. (2018). $\mathrm{CuInS} 2$ sensitized $\mathrm{TiO} 2$ hybrid nanofibers for 
improved photocatalytic $\mathrm{CO} 2$ reduction. Applied Catalysis B: Environmental, 230, 194-202.

Yang, G., Jiang, Z., Shi, H., Xiao, T., Yan, Z. (2010). Preparation of highly visible-light active Ndoped $\mathrm{TiO} 2$ photocatalyst. Journal of Materials Chemistry. 20, 5301.

Yoneyama, H. (1997). Photoreduction of carbon dioxide on quantized semiconductor nanoparticles in solution. Catalysis Today. 39, 169-175.

Yurtsever, H. A., (2015). Preparation and characterization of titania based powders and suspensions for photocatalytic applications. $\mathrm{PhD}$ Thesis, Graduate School of Engineering and Sciences of Izmir Institute of Technology.

Yurtsever, H. A., Çiftçioğlu, M. (2018). The effect of powder preparation method on the artificial photosynthesis activities of neodymium doped titania powders. International Journal of Hydrogen Energy, 43(44), 20162-20175.

Zaleska, A. (2008). Doped-TiO2: a review. Recent Patents on Engineering. 2, 157-164.

Zang, L., (2011). Energy efficiency and renewable energy through nanotechnology. USA: Springer.
Zhang, Q.-H., Han, W.-D., Hong, Y.-J., Yu, J.-G. (2009). Photocatalytic reduction of CO2 with $\mathrm{H} 2 \mathrm{O}$ on Pt-loaded TiO2 catalyst. Catalysis Today. 148, 335-340.

Zhao, Z., Fan, J., Wang, J., Li, R. (2012). Effect of heating temperature on photocatalytic reduction of $\mathrm{CO} 2$ by $\mathrm{N}-\mathrm{TiO} 2$ nanotube catalyst. Catalysis Communications. 21, 32-37.

Zhu, J., Zäch, M. (2009). Nanostructured materials for photocatalytic hydrogen production. Current Opinion in Colloid \& Interface Science. 14, 260269. 